\title{
EFEKTIFITAS PROGRAM SYAR'I: HAFALAN ALQURAN DENGAN MENGGUNAKAN METODE ONE DAY THREE LINES PADA SISWA MTSN 01 LIMAPULUH KOTA
}

\author{
Romi Maimori \\ Fakultas Tarbiyah dan Ilmu Keguruan IAIN Batusangkar \\ Jl. Sudirman No. 137 Kuburajo Lima Kaum Batusangkar \\ e-mail: maimori78@gmail.com
}

\begin{abstract}
This study was inspired by the reality that memorizing the Quran had become an activity which was avoided by most of students and uninteresting as well due to its ineffectiveness of the memorizing methods. Dealing with the phenomena, this study aimed at figuring out how One Day Three Lines method was applied di MTsN 01 Limapuluh Kota, and related factors that supported or inbibited the implementation of the method in memorizing the Quran. This study belonged to descriptive quantitative design employing evaluative model of CIPP (Contexs, Input, Proses dan Produc) Method. The data were collected through participant observation, in depth interview, questionnaire, and documentation. Data analysis were carry out by checking data trustworthiness obtained from observation, interview, documentation to figure out the context and product evaluations of One Day Three Lines memorizing method. Questionnaire was used to assess respondents' attitude toward the method. The findings showed that One Day Three Lines memorizing method applied in MTsN 01 Lima Pulub Kota was categorized effective with an average percentage was $71.9 \%$.
\end{abstract}

Kata kunci: efektivitas, hafalan Alquran, metode one day three lines

\section{PENDAHULUAN}

A lquran adalah kitab suci yang diturunkan oleh Allah Swt untuk umat Nabi Muhammad Saw melalui perantara malaikat Jibril yang berisi petunjuk dan pedoman hidup di dunia dan di akhirat. Alquran adalah kitab yang paling sempurna karena mencakup seluruh wahyu yang disampaikan kepada Nabi dan Rasul yang terdahulu, baik berupa petunjuk, perbaikan, pendidikan, pengajaran seluruh akhlak, dan budi pekerti.

Alquran merupakan mukjizat terbesar yang diberikan Allah Swt yang merupakan rahmat bagi alam semesta dan kebenaran, kesuciannya dan kemurniannya adalah universal berlaku sepanjang zaman dan Allah Swt juga yang akan menjaganya, hal ini dijamin oleh Allah Swt dalam firman-Nya:

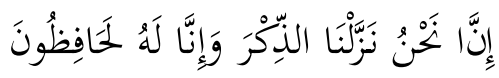

Sesungguhnya Kami-lah yang menurunkan Alquran, dan Sesungguhnya Kami benarbenar memeliharanya. (Q.S. al-Hijr [15]: 9)

Secara leksikal kata Alquran mengandung arti bacaan dan baru pada perkembangannya dianggap merujuk kepada arti teks yang dibaca maka, membaca, memahami dan menghayati alquran adalah salah satu cara guna meraih iman dan memantapkannya, karena itu Allah Swt mengecam orang-orang yang ragu dengan firman-Nya:

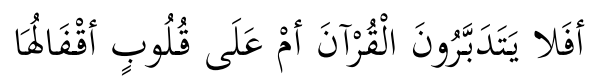

Maka Apakah mereka tidak memperhatikan Alquran ataukah hati mereka terkunci?. (Q.S. Muhammad [47]: 24).

Di dalam ayat lain menjelaskan bahwa Alquran merupakan petunjuk, hal ini dapat dilihat dalam firman Allah Swt: 


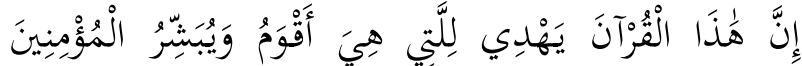

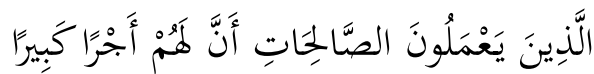

Sesungouhnya Alquran ini memberikan petunjuk kepada (jalan) yang lebih Lurus dan memberi kabar gembira kepada orang-orang Mu'min yang mengerjakan amal saleh bahwa bagi mereka ada pahala yang besar. (Q.S. Al-Isra' [17]: 9).

Dalam sebuah hadis juga dijelaskan oleh Rasulullah bahwa manusia yang terbaik adalah yang mamu mempelajari Alquran kemudian juga mau mengajarkannya:

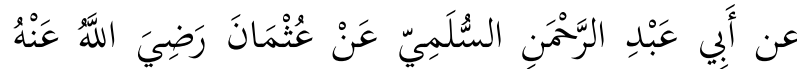

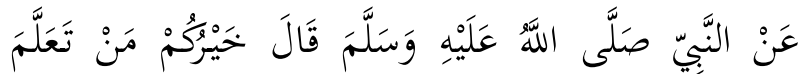

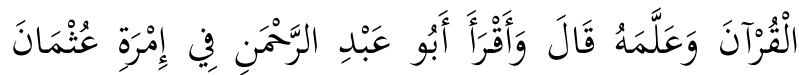

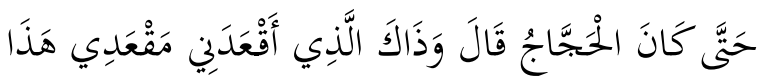

Dari Abu Abdurrahman As Sulami dari Utsman radliallahu 'anhu, dari Nabi shallallahu 'alaihi wasallam, beliau bersabda: "Orang yang paling baik di antara kalian adalah seorang yang belajar Alquran dan mengajarkannya." Abu Abdirrahman membacakan (Alquran) pada masa Utsman hingga Hajjaj pun berkata, "Dan hal itulah yang menjadikanku duduk di tempat dudukku ini.

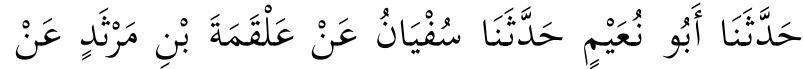

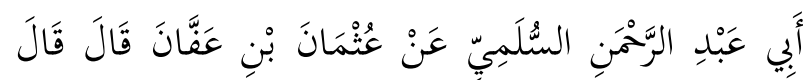

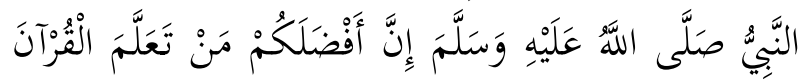

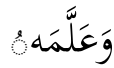

Telah menceritakan kepada kami Abu Nu'aim Telah menceritakan kepada kami Sufyan dari Alqamah bin Martsad dari Abu Abdurrahman As Sulami dari Utsman bin 'Affan ia berkata; Nabi shallallahu 'alaihi wasallam bersabda: "Orang yang paling utama di antara kalian adalah seorang yang belajar Alquran dan mengajarkannya."

Dari jabaran di atas jelas bahwa membaca, mempelajari, memahami isi kandungan Alquran adalah ibadah dan dijanjikan pahala oleh Allah Swt dan agar Alquran tetap terjaga sebagai pedoman hidup umat Islam maka lembaga pendidikan mempunyai peran yang sangat urgen dalam mewariskan nilai/ transfer of value sesuai dengan amanat Undang-undang Sistem Pendidikan Nasional yang bertujuan untuk membentuk karakter seseorang beriman dan bertaqwa kepada Tuhan Yang Maha Esa, untuk itu betapa pentingnya mengajarkan dan mempelajari Alquran maka, suatu proses pendidikan harus yang diarahkan untuk mendorong, membimbing, mengembangkan dan membina kemampuan murid membaca Alquran mengerti arti dan pokok kandungan ayat-ayat Alquran sehingga dapat meningkatkan pengetahuan, iman, dan takwa serta menjadi pedoman akhlak dan ibadah sehari-hari.

Kemudian, dalam ayat lain yang memperkuat bahwa Alquran itu dimudahkan bagi ornag-orang yang suka untuk berdzikir (mengingat Allah), dan kemudahan Alquran ini meliputi bacaannya, hafalannya, pemahamannya, perenungannya dan keajaiban-keajabainnya, dan Allah akan memberi kemudahan bagi siapa yang berkeinginan kuat untuk menghafal Alquran dengan hati yang ikhlas dengan mencari pertolongan AllahSwt

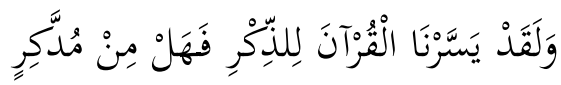

Dan Sesungguhnya telah Kami mudahkan Alquran untuk pelajaran, Maka Adakah orang yang mengambil pelajaran?. (Q.S. al-Qomar [54]:17).

Di Madrasah Tsanawiyah (MTsN) 01/MTsN 01 Lima Puluh Kota dalam mengajarkan Alquran pada mata pelajaran PTQ (Pembelajaran Tahfiz Qur'an) melaksanakan suatu metode untuk hafalan Alquran bagi siswanya dengan metode One Day Three Lines, 
sebagai salah satu mata pelajaran muatan lokal. Maka berdasarkan kondisi itu penulis tertarik untuk meneliti keefektifitas metode syar'i tersebut dalam hafalan Alquran siswa, maka penelitian ini penulis beri judul : "Efektifitas Program Syar'i: Hafalan Alquran dengan Menggunakan Metode One Day Three Lines pada Siswa MTsN 01 Lima PuluhKota.

\section{Identifikasi Masalah}

Dalam meningkatkan hafalan Alquran siswa di Madrasah Tsanawiyah (MTsN) 01 Lima Puluh Kota dengan menggunakan metode One Day Three Lines, untuk proses pelaksanaannya masih ditemui beberapa masalah yaitu pola pelaksanaan, waktu pelaksanaan metode One Day Three Lines, faktor siswa, faktor guru pembimbing, dan tempat pelaksanaannya.

\section{Batasan Masalah}

Masalah penelitian ini dibatasi pada aspek:

1. Pelaksanaan metode One Day Three Lines dalam meningkatkan hafalan Alquran siswa di Madrasah Tsanawiyah 01 Limapuluh Kota (MTsN 01 Lima Puluh Kota).

2. Tingkat efektifitas Pelaksanaan metode One Day Three Lines dalam meningkatkan hafalan Alquran siswa di Madrasah Tsanawiyah 01 Limapuluh Kota (MTsN 01 Lima Puluh Kota).

3. Faktor penghambat dan pendukung efektifitas Pelaksanaan metode One Day Three Lines dalam meningkatkan hafalan Alquran siswa di Madrasah Tsanawiyah 01 Limapuluh Kota (MTsN 01 Lima Puluh Kota).

\section{Rumusan Masalah}

Berdasarkan identifikasi dan batasan masalah yang ditetapkan, maka dapat dirumuskan permasalahan penelitian ini sebagai berikut:

1. Bagaimanakah pelaksanaan metode One Day Three Lines dalam meningkatkan hafalan Alquran siswa di Madrasah Tsanawiyah 01
Limapuluh Kota (MTsN 01 Lima Puluh Kota)?

2. Bagaimanakah tingkat efektifitas Pelaksanaan metode One Day Three Lines dalam meningkatkan hafalan Alquran siswa di Madrasah Tsanawiyah 01 Limapuluh Kota (MTsN 01 Lima Puluh Kota)?

3. Faktor-faktor apa saja yang menghambat dan mendukung efektifitas Pelaksanaan metode One Day Three Lines dalam meningkatkan hafalan Alquran siswa di Madrasah Tsanawiyah 01 Limapuluh Kota (MTsN 01 Lima Puluh Kota)?

\section{Kajian Teoritis}

Alquran menurut bahasa (etimologi) berarti bacaan atau yang dibaca, tidak ada satupun bacaan di dunia ini yang menandingi keindahan bacaan Alquran, seperti yang dijelaskan Allah Swt dalam firman-Nya:

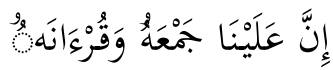

Sesungguhnya atas tanggungan kamilah mengumpulkannya (di dadamu) dan (membuatmu pandai) membacanya. (Q.S. AlQiyyamah [75]: 17).

Sedangkan menurut istilah (terminologi) adalah kalamullah (firman Allah Swt) yang diturunkan kepada Nabi Muhammad Saw dengan perantara malaikat jibril, menjadi mukjizat atas kenabiannya, tertulis dalam bahasa Arab yang sampai kepada kita dengan jalan mutawatir dan membacanya adalah ibadah.

Dari pengertian di atas dapat disimpulkan bahwa unsur-unsur makna yang terkandung di dalam Alquran adalah:

1. Alquran adalah kalamullah.

2. Alquran merupakan mukjizat Nabi Muhammad Saw sebagai bukti kenabian dan kerasulannya.

3. Alquran bukan karangan Nabi Muhammad tetapi adalah wahyu yang diturunkan oleh AllahSwt. 
4. Alquran merupakan bacaan mulia dan membacanya adalah ibadah.

5. Alquran akan senantiasa terpelihara dari kesalahan dan pemalsuan.

6. Tidak akan ada seorangpun yang akan mampu membuat yang serupa dengan Alquran.

Terdapat beberapa sifat Alquran yaitu:

1. Ajaran-ajaran dan hukum-hukumnya bersifat universal, sehingga tetap sesuai untuk setiap umat, tempat dan masa.

2. Ajaran-ajaran dan hukum-hukumnya terang dan logis, sehingga mudah untuk dipahami dan diamalkan.

3. Ajaran-ajaran dan hukum-hukumnya sangat bermanfaat untuk kehidupan pribadi dan masyarakat.

4. Ajaran-ajaran dan hukum-hukumnya tidak hanya mementingkan masalah duniawi atau ukhrawi saja, melainkan untuk keduaduanya.

5. Alquran sangat menghormati akal dan kemajuan pikiran manusia, karena Alquran tidak akan menghalangi kemajuan ilmu pengetahuan sehingga ilmu tersebut tetap diarahkan untuk kemaslahatan umat manusia dan pengabdian kepada Allah Swt.

Dari uraian di atas jelaslah bahwa nilai-nilai yang terkandung di dalam Alquran teramat agung dan sempurna dengan ajaran-ajaran yang terkandung di dalamnya serta hukumhukumnya yang berisi tentang petunjuk bagi orang-orang beriman dan mau mengamalkannya

Sedangkan hafalan Alquran adalah melafazdkan ayat-ayat /surat-surat dalam Alquran di luar kepala (tanpa melihat buku atau catatan lain) dan aktivitas mencamkan dengan sengaja dan dikehendaki dengan sadar dan sungguh-sungguh. Menghafal Alquran pada hakikatnya adalah suatu upaya untuk menambah kedekatan dengan Alquran karena dengan menghafal jiwa dan otak kita akan terus menyerap lantunan ayat-ayat Alquran yang diulang-ulang begitu banyak oleh lidah kita.

Hukum menghafal Alquran menurut para ulama dan Abdul Abas Ahmad binMuhammad Aajjurjani, berkata dalam kitab assyafii bahwa hukum menghafal mengikuti Nabi Muhammad Saw adalah fardhu kifayah. mengikuti nabi Muhammad Saw untuk menjaga nilai mutawatir. Apabila hal ini tidak dilakukan maka seluruh umat Islam ikut menanggung dosa, dan ketetapan hukum seperti itu tidak berlaku pada kitab-kitab Samawi yang lain. Dengan demikian jelaslah bahwa menghafal Alquran hukumnya adalah fardhu kifayah, fardhu kifayah sebagaimana yang dimaksud ulama yaitu apabila suatu pekerjaan di suatu wilayah tidak ada yang mengerjakan maka semua orang yang ada di wilayah tersebut kena (berdosa) semua. Karena tidak melaksanakan perbuatan tersebut. Sedangkan menghafal sebagian surat Alquran seperti Al-Fatihah, atau selainnya adalah fardhu 'ain. Hal ini mengingat bahwa Al-Fatihah adalah termasuk kepada rukun shalat.

Adapun prinsip dasar agar seseorang mampu menghafal Alquran adalah:

1. Mengikhlaskan niat hanya untuk mencari ridha Allah Swt

2. Memakaikan ilmu tajwid dalam setiap menghafal.

3. Menentukan target hafalan setiap hari.

4. Menuntaskan satu persatu ayat yang dihafal sebelum masuk pada hafalan baru.

5. Menghafal dengan menggunakan satu mushaf.

6. Memahami informasi dari ayat supaya otak bisa terkesan dan membuat deskripsinya.

7. Tidak pindah ke surat lain sebelum kuat hafalan surat yang sudah dihafalkan.

8. Selalu memperdengarkan bacaan pada guru.

9. Selalu menjaga hafalan dengan murajaah/ mengulang setiap hari.

10. Bersungguh-sungguh dalam memperhatikan ayat-ayat yang serupa. 
11. Mencatat ayat yang sulit dihafal supaya tambah mudah menghafalnya.

Di samping prinsip-prinsip di atas juga harus diperhatikan kaidah dan ketentuan dalam menghafal Alquran, yaitu:

1. Menghafal melalui seorang guru atau syekh yang bisa membenarkan hafalan jika salah.

2. Hafalkanlah setiap hari sebanyak 2 halaman, 1 halaman setelah Subuh dan 1 halaman setelah Ashar atau Maghrib, dengan cara ini insya Allah anda akan bisa menghafal Alquran secara mutgin dalam kurun waktu satu tahun, akan tetapi jika anda memperbanyak kapasitas hafalan setiap harinya maka anda akan sulit untuk menjaga dan memantapkannya, sehingga hafalan anda akan menjadi lemah dan banyak yang dilupakan.

3. Hafalkanlah mulai dari surat An-Nas hingga surat Al-Baqarah (membalik urutan Alquran), karena hal itu lebih mudah.

4. Dalam menghafal hendaknya menggunakan satu mushaf tertentu baik dalam cetakan maupun bentuknya, hal itu agar lebih mudah untuk menguatkan hafalan dan agar lebih mudah mengingat setiap ayatnya serta permulaan dan akhir setiap halamannya.

5. Setiap yang menghafalkan al-quran pada 2 tahun pertama biasanya akan mudah hilang apa yang telah ia hafalkan, masa ini disebut masa "tajmi"' (pengumpulan hafalan), maka jangan bersedih karena sulitnya mengulang atau banyak kelirunya dalam hafalan, ini merupakan masa cobaan bagi para penghafal Alquran, dan ini adalah masa yang rentan dan bias menjadi pintu setan untuk menggoda dan berusaha untuk menghentikan dari menghafal, maka jangan pedulikan godaannya dan teruslah menghafal, karena meghafal Alquran merupakan harta yang sangat berharga dan tidak tidak diberikan kecuali kepada orang yang dikaruniai Allah Swt, akhirnya kita memohon kepada-Nya agar termasuk menjadi hamba-hamba-Nya yang diberi taufiq untuk menghafal dan mengamalkan kitab-Nya dan mengikuti sunnah nabi-Nya dalam kehidupan yang fana ini. Amin ya rabal 'alamin.

\section{Metode One Day Three Lines}

Metode One Day Three Lines diterapkan di MTsN 01 Limapuluh Kota dengan cara berarti satu hari siswa diharapkan dapat menghafalkan Alquran empat baris sehingga ditargetkan dalam waktu lebih kurang enam bulan siswa sudah mampu menghafalkan satu juz Alquran dan pada tahap awal siswa diwajibkan dulu menghafalkan juz ke-30, kepada siswa masingmasing diberikan buku pegangan metode one day three lines ini melalui tiga tahapan proses yang harus dilalui untuk mendapatkan hafalan yang baik, yaitu: proses tahsin, tahfidz dan taqrir.

Proses tahsin adalah membenarkan bacaan. Proses tahfiz yaitu membaca berulang-ulang sampai hafal. Sedangkan taqrir adalah mengulang kembali ayat yang sudah dihafal sebelum menambahnya.

Dipilihnya metode One Day Three Linessebagai salah satu program unggulan di MTSN 01 Limapuluh Kota dengan menentukan sendiri baik metodologi maupun target-target yang ditetapkan kepada para siswa. Adapun panduan metode One Day Three Lines, adalah:

1. Mulailah pada kolom pertama dengan mengisi hari dan tanggal.

2. Lihatlah bacaan ayat yang akan dihafal dengan penuh keinginan untuk menghafalnya.

3. Perhatikan tajwid bacaan ayat yang sedang ditahsinkan oleh guru.

4. Bacalah dengan penuh memperhatikan tajwidnya.

5. Bacalah sampai tidak ada salah lagi dan beri tanda tangan pada kolom tahsin.

6. Bacalah sampai hafal dengan cara membaca dengan berulang-ulang 
7. Setelah hafal, setorkan hafalannya dan beri tanda tangan pada tahfiz.

8. Sebelum menambah, ulang kembali hafalannya dan bila sudah lancar beri tanda tangan pada kolom taqrir.

9. Kolom taqrir adalah penentu boleh atau tidaknya menambah hafalan pada kolom berikutnya.

\section{METODE PENELITIAN}

\section{Jenis dan Pendekatan Penelitian}

Penelitian ini termasuk dalam penelitian evaluatif (evaluative research) dengan menggunakan pendekatan deskriptif dan kuantitatif. Penelitian dengan pendekatan deskriptif kuantitatif menurut Sugiyono dapat digunakan bersama untuk meneliti objek yang sama tetapi tujuannya berbeda. Dalam penelitian ini, penelitian deskriptif digunakan untuk menjelaskan mengenai pelaksanaan metode one day three lines pada program hafalan Alquran siswa di MTsN 01 Limapuluh Kota, sedangkan penelitian kuantitatif digunakan untuk mengetahui tingkatan efektivitas pelaksanaan metode one day three lines pada program hafalan Alquran siswa diMTsN 01 Limapuluh Kota.

Penelitian ini dilaksanakan untuk memperoleh data serta menghasilkan kesimpulan yang ada di lapangan sehubungan dengan evaluasi program Tahfiz di MTsN 01 Lima Puluh Kota dengan model evaluasi CIPP (Context, Input, Process dan Product), dimana peneliti bermaksud mengumpulkan data tentang implementasi program.Penelitian evaluatif pada dasarnya terpusat pada rekomendasi akhir yang menegaskan bahwa suatu obyek evaluasi dapat dipertahankan, ditingkatkan, diperbaiki atau bahkan diberhentikan sejalan dengan data yang diperoleh.

\section{Waktu dan Tempat Penelitian}

Penelitian ini dilaksanakan di MTsN 01 Limapuluh Kota yang beralamat di Padang Japang Kec. Guguak, Kab. Limapuluh Kota pada tanggal 28 Juli s/d 28 September 2015. Penelitian dilakukan dengan beberapa tahap; observasi awal, penyusunan proposal, seminar proposal, perizinan, pengumpulan data, analisis data dan penyusunan laporan penelitian.

\section{Sumber Data}

\section{Data Primer}

Sumber data primer diartikan sebagai sumber data yang diperoleh langsung dari subjek penelitian dengan mengenakan alat pengukuran atau alat pengambilan data langsung pada subjek sebagai sumber informasi yang dicari. Adapun sumber data primer dapat penelitian ini adalah kepala sekolah dan guru mata pelajaran tahfiz pada MTsN 01 Lima Puluh Kota sebanyak 4 orang.

\section{Data Sekunder}

Sumber data sekunder dalam penelitian ini berbentuk kurikulum tahfiz MTsN 01 Lima Puluh Kota, dokumen-dokumen pendukung lainnya.

\section{Teknik Pengumpulan Data} adalah:

Teknik pengumpulan data penelitian ini

\section{Observasi}

Metode observasi merupakan alat pengumpul data yang digunakan untuk mengukur tingkah laku atau proses terjadinya suatu kegiatan yang diamati, dan dalam penelitian ini, metode observasi yang dilakukan berupa pengamatan dan pencatatan secara sistematik terhadap gejala yang tampak pada pelaksanaan program Tahfiz dengan metode One Day Three Line di MTsN 01 Lima Puluh Kota. 


\section{Kuesioner/Angket}

Kuesioner atau angket merupakan teknik pengumpulan data yang dilakukan dengan cara memberi seperangkat pertanyaan atau pernyataan tertulis kepada responden untuk dijawabnya. Adapun metode pengumpulan data dalam penelitian ini adalah dengan menggunakan angket tertutup dimana responden tidak mempunyai kesempatan lain dalam memberikan jawabannya selain jawaban yang telah disediakan dalam daftar pernyataan tersebut.

\section{Interview/ Wawancara}

Metode wawancara ini digunakan untuk mendapatkan informasi langsung dari responden yang memiliki keterkaitan langsung dengan pelaksanaan program tahfiz dengan metode One Day Three Lines di MTsN 01 Lima
Puluh Kota, yaitu kepala sekolah dan guru pembina/ guru mata pelajaran tahfiz.

\section{Dokumentasi}

Metode dokumentasi adalah metode mencari data mengenai hal-hal atau variabel yang berupa catatan, transkrip, buku, majalah, surat kabar, notulen rapat, agenda, dan sebagainya. Metode dokumentasi dalam penelitian ini adalah data-data atau dokumendokumen yang dapat dipertanggungjawabkan kebenarannya terkait dengan program tahfiz dengan metode One Day Three Lines di MTsN 01 Lima Puluh Kota, berupa gambaran umum MTsN 01 Lima Puluh Kota, struktur dan muatan kurikulum. Terkait denganjenis data dan metode pengumpulan data, dapat dilihat berdasarkan Tabel 1. Jenis Data dan Metode Pengumpulan Data berikut ini:

Tabel 1. Jenis Data dan Metode Pengumpulan Data

\begin{tabular}{|c|c|c|c|c|c|c|}
\hline \multirow{2}{*}{ No } & \multirow{2}{*}{$\begin{array}{c}\text { Komponen } \\
\text { Evaluasi } \\
\end{array}$} & \multirow{2}{*}{ Aspek yang dievaluasi } & \multicolumn{4}{|c|}{ Metode Pengumpulan Data } \\
\hline & & & Angket & Wawancara & Observasi & Dokumentasi \\
\hline 1. & Konteks & $\begin{array}{l}\text { - Kurikulum Tahfiz } \\
\text { - Sistem Pembelajaran } \\
\text { Tahfiz } \\
\text { - Buku Panduan Tahfiz }\end{array}$ & $\begin{array}{l}\sqrt{ } \\
\sqrt{ }\end{array}$ & $\sqrt{ }$ & & $\sqrt{ }$ \\
\hline 2. & Input & $\begin{array}{ll}\text { - } & \text { Antusisme siswa } \\
\text { - Fasilitas pendukung } \\
\text { - Waktu pelaksanaan }\end{array}$ & $\begin{array}{l}\sqrt{ } \\
\sqrt{ } \\
\sqrt{ }\end{array}$ & $\begin{array}{l}\sqrt{ } \\
\sqrt{ }\end{array}$ & $\begin{array}{l}\sqrt{ } \\
\sqrt{ }\end{array}$ & \\
\hline 3. & Proses & $\begin{array}{l}\text { - Pelaksanaan program } \\
\text { tahfiz } \\
\text { - Upaya Guru } \\
\text { - Pelaksanaan } \\
\text { kurikulum }\end{array}$ & $\sqrt{ }$ & $\begin{array}{l}\sqrt{ } \\
\sqrt{ } \\
\sqrt{ }\end{array}$ & & $\sqrt{ }$ \\
\hline 4. & Produk & $\begin{array}{l}\text { Keberhasilan Program } \\
\text { Tahfiz Metode One Day } \\
\text { Three Lines }\end{array}$ & $\sqrt{ }$ & $\sqrt{ }$ & $\sqrt{ }$ & $\sqrt{ }$ \\
\hline
\end{tabular}




\section{Teknik Analisa Data}

Dalam penelitian ini peneliti melakukan pengecekan data yang berasal dari data observasi, dokumentasi dan wawancara, kemudian ditelaah dengan tujuan untuk mengetahui bagaimana evaluasi konteks program tahfiz metode One Day Three Lines dan evaluasi produk program One Day Three Lines di MTsN 01 Lima Puluh Kota. Sedangkan untuk angket menggunakan skala Likert yang berisi pernyataan yang sistematis untuk menunjukkan sikap seorang responden terhadap butir pernyataan, dengan memberi bobot pada jawaban dari tiap sumber data, yaitu: 1). Jawaban Sangat Efektif diberi bobot 5 , 2). Jawaban Efektif diberi bobot 4. 3). Jawaban Cukup Efektif diberi bobot 3. 4). Jawaban Tidak Efektif diberi bobot 2, dan 5). Jawaban Sangat Tidak Efetif diberi Bobot 1. Data dari hasil angket akan dianalisis dengan menggunakan rumus, sebagai berikut:

$$
\text { Nilai }=\frac{\text { Skor } \text { Yang Dinilai }}{\text { Skor Maksimun }} X 100
$$

Dan hasil perhitungan tersebut akan dikonversikan ke dalam kategori berdasarkan pendapat Suharsimi Arikunto yaitu:

Tabel 2.

Rerata Skor dan Kategori

\begin{tabular}{|c|c|}
\hline Rerata Skor & Kategori \\
\hline $81-100$ & Sangat Efektif \\
\hline $61-80$ & Efektif \\
\hline $41-60$ & Cukup Efektif \\
\hline $21-40$ & Tidak Efektif \\
\hline $00-21$ & Sangat Tidak Efektif \\
\hline
\end{tabular}

\section{HASIL PENELITIAN}

Pelaksanaan program tahfiz dengan menggunakan metode One Day Three Lines ini dengan mengevaluasi beberapa komponen, yaitu:

Tabel 3. Aspek yang Dinilai

\begin{tabular}{|c|l|}
\hline No & \multicolumn{1}{|c|}{ Aspek yang di evaluasi } \\
\hline 1 & Program tahfiz dengan metode One Day Three Lines \\
\hline 2 & Guru pembimbing \\
\hline 3 & Fasilitas Pendukung \\
\hline 4 & Waktu pelaksanaan \\
\hline 5 & Peserta/siswa \\
\hline
\end{tabular}

Komponen-komponen ini telah dikembangkan ke dalam bentuk instrumen penelitian dan disampaikan kepada sumber data yaitu berupa daftar wawancara, angket dan observasi, dan hasilnya dikategorikan ke dalam rentang skor yang ditetapkan oleh Suharsimi Arikunto, seperti digambarkan pada tabel 2

Dari hasil pengolahan data dan hasil wawancara dengan sumber data dari komponen penelitian bahwa: 


\section{Pengolahan dari Instrumen}

Pengolahan dari instrumen data penelitian (terlampir), secara umum bahwa pelaksanaan program tahfiz dengan menggunakan metode One Day Three Lines berada dalam rentang Efektif, meskipun ada beberapa komponen yang masih berada dalam rentang Cukup Efektif, yaitu Siswa mampu menghafal dengan lancar 1 juz dalam waktu 6 bulan, karena sesuai dengan target awal dari sekolah dan guru pembimbing dengan penerapan metode One Day Three Lines ini siswa diharapkan dapat menghafal Alquran satu juz itu dalam waktu 6 bulan. Sesuai dengan angket yang dijawab oleh guru pembimbing tahfiz masih ada indikator dengan jawaban 1 artinya sangat tidak efektif ini dapat diinterpretasikan bahwa secara fisik sudah ada dan sudah dalam perencanaan tetapi belum terealisasi dengan baik. Dan tujuan utama dari program tahfiz ini bisa menghafal Alquran sampai 30 juz sampai menamatkan pendidikan pada MTsN 01 Lima Puluh Kota belum bisa terealisasi, ini terlihat dari total jumlah siswa 492 orang hanya 2 orang saja siswa yang mampu menghafal Alquran sampai 30 Juz.

Faktor Pendukung dan Penghambat dari Program Tahfiz dengan Metode One Day Three Lines di MTsN 01 Lima Puluh Kota
Faktor pendukung dan penghambat dari program tahfiz dengan metode One Day Three Lines di MTsN 01 Lima Puluh Kota

Faktor pendukung dari pelaksanaan metode tahfiz One Day Three Lines ini adalah bahwa kegiatan ini mendapat dukungan penuh dari sekolah dengan menjadikan program ini menjadi program sekolah dan menjadikan program kegiatan ini masuk dalam kurikulum sekolah sebagai mata pelajaran muatan lokal, yang diwajibkan kepada semua siswa MTsN 01 Lima Puluh Kota, dan sekolah juga memberikan reward kepada siswa melalui wisuda tahfiz yang dilakukan oleh pihak sekolah.

Faktor pengahambat dari pelaksanaan metode tahfiz One Day Three Lines ini adalah dari waktu pelaksanaan kegiatan tahfiz ini yang harus dibatasi oleh jam pelajaran tahfiz yang masih kurang memadai, kemudian hal lain yang juga menjadi kendala adalah minat dan motivasi dari siswa untuk menghafal Alquran.

\section{Persentase}

Berdasarkan analisis data penelitian program tahfiz dengan metode One Day Three Lines pada tiap komponen penelitian dipersentasekan sesuai dengan pengkategoriannya dapat dilihat pada tabel dan diagram berikut:

Tabel 4. Rerata Skor, Kategori, dan Persentase

\begin{tabular}{|c|c|c|}
\hline Rerata Skor & Kategori & Persentase \\
\hline $81-100$ & Sangat Efektif & 8.16 \\
\hline $61-80$ & Efektif & 88.44 \\
\hline $41-60$ & Cukup Efektif & 5.18 \\
\hline $21-40$ & Tidak Efektif & 0.14 \\
\hline $00-21$ & Sangat Tidak Efektif & 0.3 \\
\hline
\end{tabular}


Diagram 1. Rerata Skor, Kategori, dan Persentase

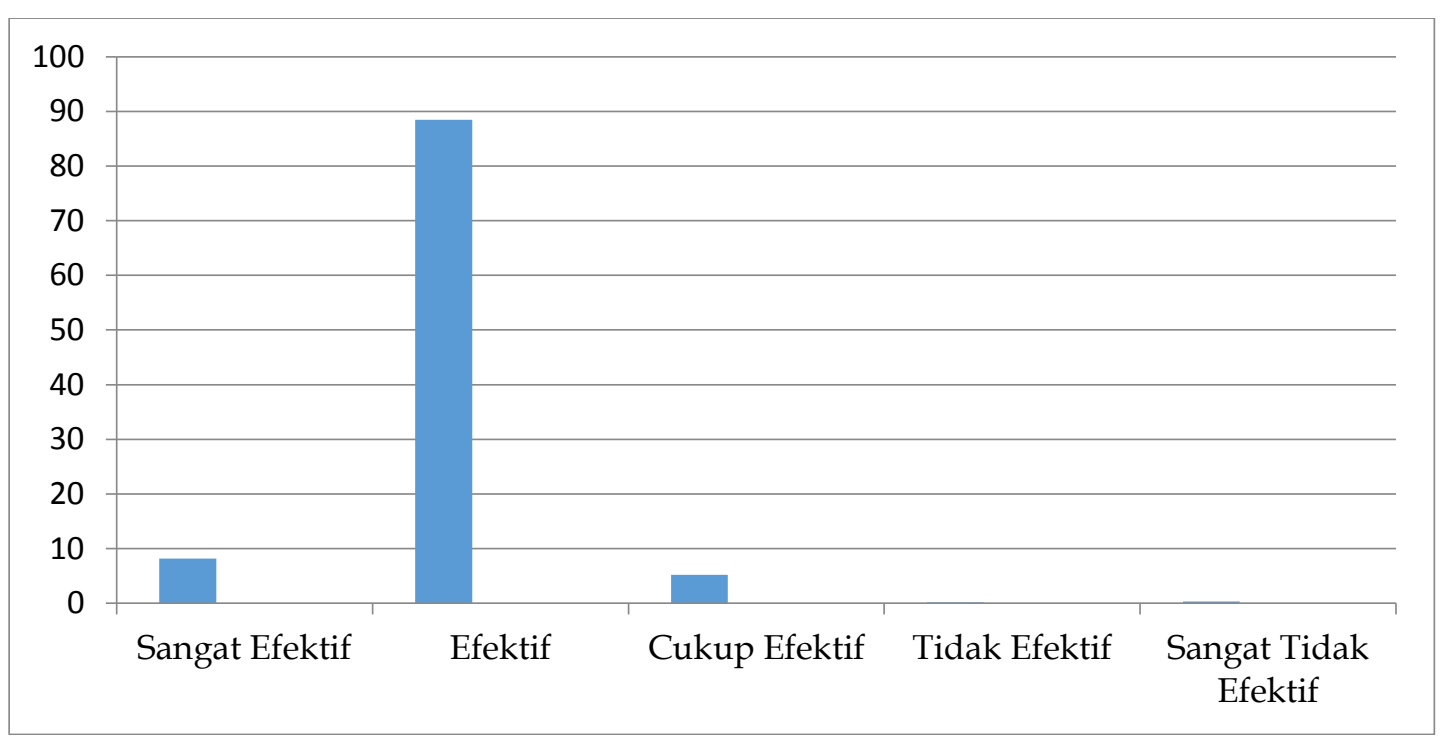

Dari analisis data di atas dapat dilihat bahwa tingkat efektifitas pelaksanaan program tahfiz dengan menggunakan metode One Day Three Lines adalah berada pada kategori Efektif dengan nilai capaian $88,44 \%$.

Analisis berikutnya adalah menganalisis pada masing-masing komponen,sub komponen dan indikator dari pelaksanaan program tahfiz dengan metode One Day Three Lines di MTsN 01 Lima Puluh Kota, berikut diuraikan perhitungan rerata skor pada setiap komponen. Hasil perhitungan rerata tiap-tiap komponen dari evaluasi pelaksanaan program tahfiz Alquran dengan metode One Day Three Lines dapat disajikan pada tabel berikut:

Tabel 5. Hasil Perhitungan Rerata Tiap-tiap Komponen dari Evaluasi Pelaksanaan Program Tahfiz Alquran dengan Metode One Day Three Line

\begin{tabular}{|c|c|c|c|c|c|}
\hline No & Indikator & $\begin{array}{c}\text { Jumlah } \\
\text { Item }\end{array}$ & $\begin{array}{c}\text { Total } \\
\text { Skor }\end{array}$ & Rerata & Kategori \\
\hline 1. & $\begin{array}{c}\text { Context } \\
\text { (konteks) }\end{array}$ & 4 & 312 & 78 & Efektif \\
\hline 2. & $\begin{array}{c}\text { Input } \\
\text { (masukan) }\end{array}$ & 5 & 384 & 76.8 & Efektif \\
\hline 3. & $\begin{array}{c}\text { Process } \\
\text { (proses) }\end{array}$ & 7 & 476 & 68 & Efektif \\
\hline 4. & $\begin{array}{c}\text { Product } \\
\text { (produk) }\end{array}$ & 5 & 324 & 64.8 & Efektif \\
\hline \multicolumn{2}{|c|}{$\begin{array}{c}\text { Total pelaksanaan tahfiz } \\
\text { dengan metode One Day Three } \\
\text { Lines }\end{array}$} & 1496 & 71.9 & Efektif \\
\hline
\end{tabular}




\section{Diagram 2. Hasil Perhitungan Rerata Tiap-tiap Komponen dari Evaluasi Pelaksanaan Program Tahfiz Alquran dengan Metode One Day Three Lines}

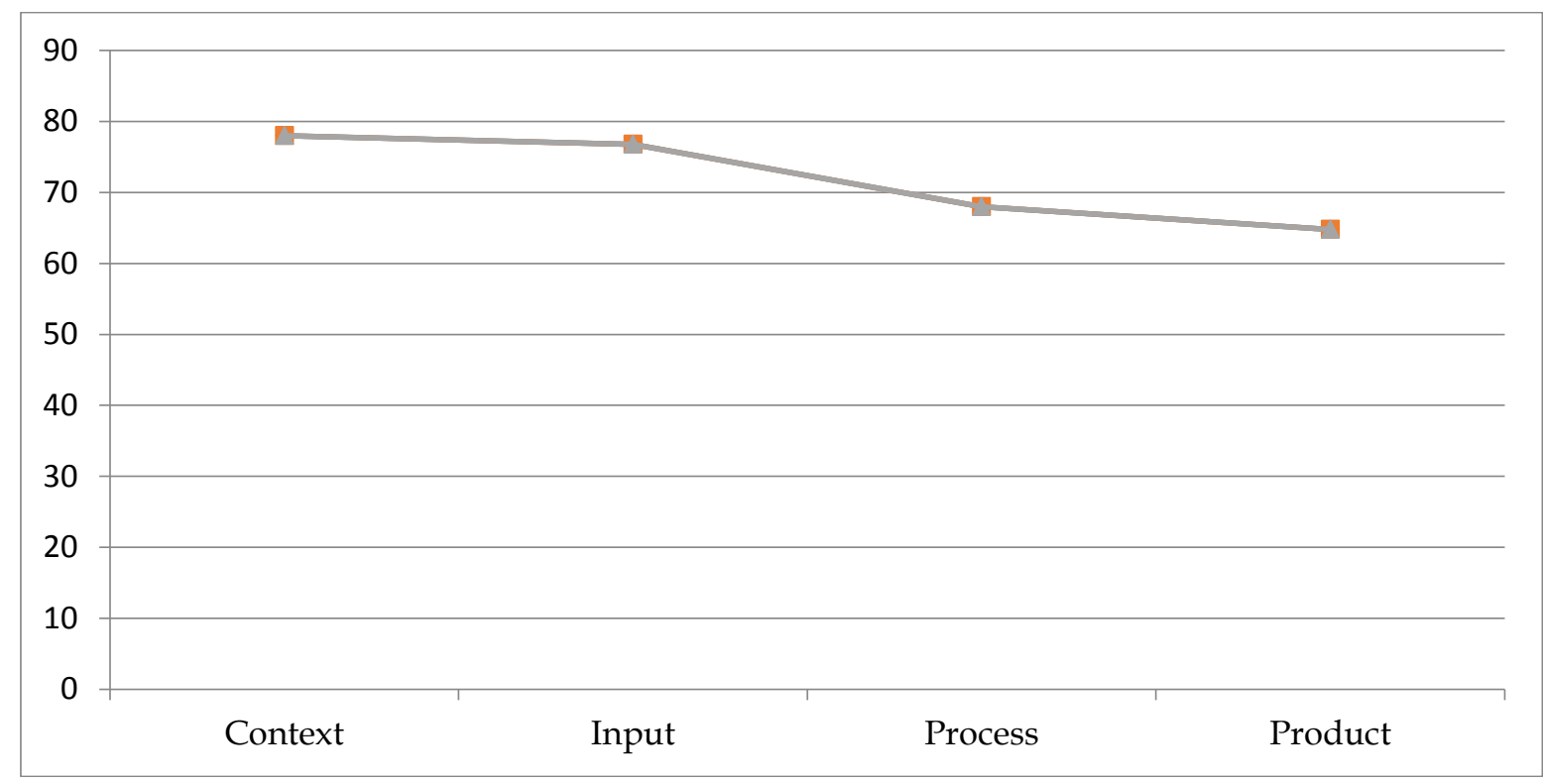

Dari analisis data di atas dari hasil evaluasi program tahfiz dengan metode One Day Three Lines di MTsN 01 Lima Puluh Kota berdasarkan Indikator penilaian program yang telah dilaksanakan berada pada rerata 71.9 yaitu pada kategori Efektif.

\section{PENUTUP}

\section{Kesimpulan}

Berdasarkan analisis data dan pembahasan dari program tahfiz dengan menggunakan metode One Day Three Lines ini, dapat diambil kesimpulan sebagai berikut.

1. Bahwa pelaksanaan program tahfiz Alquran dengan menggunanakan metode One Day Three lines di MTsN 01 Lima Puluh Kota berada dalam rerata 71.9 yaitu berada dalam kategori Efektif.

2. Meskipun dari deskripsi data penelitian sudah program kegiatan Tahfiz di MTsN 01 Lima Puluh Kota berada pada kategori efektif, namun masih ada beberapa komponen/ indikator yang harus menjadi perhatian, yaitu jumlah rasio guru mata pelajaran/ guru pembina tahfiz dan siswa yang masih belum berimbang, waktu pelaksanaankegiatan tahfiz yang masih terbatas hanya pada jam pelajaran yang dijadwalkan dalam mata pelajaran Tahfiz yang masuk sebagai kurikulum muatan lokal di MTsN 01 Lima Puluh Kota.

\section{DAFTAR KEPUSTAKAAN}

Departemen Pendidikan dan Kebudayaan, 2002. Kamus Besar Bahasa Indonesia edisi ketiga, Jakarta: PT Balai Pustaka.

Muhaemin Zen, 1985. Tata Cara dan Problematika Menghafal Alquran, Jakarta: AlHusna,

Muhammad Abdul Halim, 1999. Memahami Alquran: Pendekatan Gaya dan Tema, Bandung: Penerbit Marja.

Nana Sudjana dan Ibrahim, 1998. Penelitian dan Penilaian Pendidikan, Bandung: Sinar Baru. 
Nawabuddin, Abdurrabb, 1993. Kaifa Tahfazul Qur'an (terj. Metode Praktis Hafal Alquran, S. Ziyad Abbas), Jakarta: Firdaus.

Rauf, Abdul Azis Abdur, 2008. 17 Motivasi Berinteraksi dengan Alquran, Bandung: Mesjid Raya Habiburrahman PT Dirgantara Indonesia

2009. Andapun Bisa Menjadi Hafidz Alquran, Jakarta: Markaz Alquran.

Sugiono, 2010. Metode Penelitian Pendidikan Penekatan Kuantitatif, Kualitatif dan R\&D, Bandung: Alfabeta.

Suharsimi Arikunto, 2010. Prosedur Penelitian Suatu Pendekatan Praktik, Jakarta: Rineka Cipta.
Sumadi Suryabrata, 1990. Psikologi Pendidikan, Jakarta: Rajawali Press.

Suprayogo, Imam dan Tobrani, 2001. Metodologi Penelitian Sosial-Agama (Bandung: PT Rosda Karya.

Syaikh Manna Al-Qaththan, 2007. Pengantar Studi Ilmu Alquran, Terj. Ainur Rafiq, Jakarta: Pustaka Al-Kautsar.

Thabathaba'i, MH. Allamah, 1987. Mengungkap Rahasia Alquran, Penerjemah: A. Malik Madany dan Hamim Ilyas, Bandung: Mizan.

Wijaya, Ahsin, 1994. Bimbingan Praktis Menghafal Alquran, Jakarta: Bumi Aksara. 